\title{
$O$ difícil acesso a serviços de média complexidade do SUS: o caso da cidade de São Paulo, Brasil*
}

\author{
I ' Sandra Maria Spedo, 2 Nicanor Rodrigues Da Silva Pinto, \\ ${ }^{3}$ Oswaldo Yoshimi Tanaka I
}

Resumo: O acesso aos serviços de média complexidade tem sido apontado, por gestores e pesquisadores, como um dos entraves para a efetivação da integralidade do SUS. Este artigo teve o objetivo de avaliar mecanismos utilizados pela gestão do SUS, no município de São Paulo, para garantir acesso à assistência de média complexidade, durante o período de 2005 a 2008. Optou-se pela estratégia de estudo de caso, utilizando as seguintes fontes de evidência: entrevistas com gestores; grupo focal com usuários e observação participante. Utilizouas técnica de análise temática, a partir do referencial teórico da integralidade da assistência, na dimensão da organização de serviços. Buscou-se descrever os caminhos percorridos pelos usuários para acessar os serviços da média complexidade, a partir da visão dos gestores e dos próprios usuários. A média complexidade foi identificada, pelos gestores, como o "gargalo" do SUS e um dos principais obstáculos para a construção da integralidade. Para enfrentar essa situação, o gestor municipal investiu na informatização dos serviços, como medida isolada e, ainda, sem considerar a necessidade dos usuários. Sendo assim, essa incorporação tecnológica teve pouco impacto na melhoria do acesso, o que se confirmou no relato dos usuários. Discute-se que para o enfrentamento de um problema tão complexo são necessárias ações articuladas, tanto no âmbito da política de saúde, quanto da organização dos serviços, bem como a (re)organização do processo de trabalho em todos os níveis do sistema de saúde.

> Palavras-chave: média complexidade; integralidade; gestão em saúde; Sistema Único de Saúde; política de saúde.

\author{
1 Médica Sanitarista \\ Departamento de Medicina \\ Preventiva, Unifesp. Mestre \\ em Saúde Coletiva (Unicamp) \\ Doutora em Saúde Pública \\ (USP). Endereço eletrônico: \\ smspedo@unifesp.br \\ ${ }^{2}$ Médico Sanitarista, \\ Departamento de Medicina \\ Preventiva, Unifesp. Mestre em \\ Ciências da Saúde (Unifesp). \\ Doutor em Saúde Pública (USP). \\ Endereço eletrônico: nrspinto@ \\ unifesp.br \\ ${ }^{3}$ Professor Titular, \\ Departamento de Práticas, \\ Faculdade de Saúde Pública, \\ USP. Endereço eletrônico: \\ oytanaka@usp.br
}


O processo de construção do SUS é marcado por uma expressiva extensão da cobertura e do acesso dos cidadãos aos serviços de saúde. A partir de meados da década de 1990, vem ocorrendo um importante incremento de serviços de atenção básica $(\mathrm{AB})$, induzidos pelo Ministério da Saúde por meio da habilitação dos municípios a distintas modalidades de gestão do sistema de saúde e de financiamento diferenciado, estabelecidos na NOB-SU96. A criação do piso de atenção básica (PAB) foi identificada por Bodstein (2002) como a principal estratégia do governo para operacionalizar a prioridade da $\mathrm{AB}$. Esse se constituiu, ainda, em importante mecanismo de indução para viabilizar o Programa de Saúde da Família (PSF), apresentado como estratégia para mudança do modelo de atenção.

Em 2006, o Ministério da Saúde reafirmou o papel estratégico da AB para a implementação do SUS. Essa deveria se consolidar enquanto porta de entrada preferencial e eixo orientador para estruturação dos sistemas locais de saúde (BRASIL/MS, 2007). Contudo, esse movimento de priorização da $\mathrm{AB}$, na última década, não foi acompanhado de investimento semelhante na organização dos demais níveis de atenção do sistema, bem como na articulação entre eles no sentido de garantir a continuidade do cuidado, visando à integralidade da atenção. Santos e Gerschman (2004, p. 803), ao analisarem a segmentação da oferta de serviços de saúde no Brasil, afirmam que "o SUS hoje parece estar caminhando no sentido do 'plano de cuidados básicos'” e abrindo mão da prestação direta de serviços de maior complexidade, que ficariam para a iniciativa privada.

Nessa direção, gestores de distintas esferas de governo têm assinalado que a dificuldade de acesso aos serviços especializados, ou à média complexidade, representa um dos principais entraves para garantir a integralidade da atenção. Segundo avaliação de um presidente do Conselho de Secretários Municipais de Saúde do Estado de São Paulo (COSEMS-SP), há "um estrangulamento no acesso aos procedimentos de média complexidade. Isso afeta todos os municipios" (PIMENTA, 2005). O ministro da Saúde também considerou, em entrevista, que o acesso à atenção especializada é "um desafio importante" para o SUS, na medida em que envolve questôes complexas, relacionadas à qualidade dos serviços, à precarização dos salários, desorganização do sistema, falta de integração e articulação em vários níveis, e, ainda, ao subfinanciamento. "Se o ministério e 
seus parceiros não conseguirem dar respostas ao desafio da atenção ambulatorial e hospitalar das grandes cidades, eu teria fracassado" (TEMPORÃO, 2007, p. 12).

Esse problema foi identificado, também, em uma avaliação do processo de implementação do PSF em municípios brasileiros, realizado pelo Ministério da Saúde entre 2001 e 2002. Uma das conclusões apresentadas nessa avaliação foi que "o apoio diagnóstico e a referência para atenção especializada ainda foram insuficientes para garantir a resolubilidade e a continuidade da atenção às populaçôes assistidas pelo Programa Saúde da Familia" (BRASIL/MS, 2004, p. 24). Outros estudos, com abordagens distintas, contemplaram avaliações semelhantes ao considerar que a resolutividade da $\mathrm{AB}$ depende, em grande medida, do acesso a exames e serviços especializados (TEIXEIRA, 2003; MENDES, 2004; FEUERWERKER, 2005; ESCOREL et al., 2007).

Vale ressaltar que a resolutividade da $\mathrm{AB}$ está associada a outros fatores, tais como questôes relacionadas à estrutura física dos serviços, processo e gestão do trabalho e capacitação dos profissionais que, por sua vez, repercutem na demanda por serviços especializados. É importante considerar, ainda, o protagonismo dos usuários que, sob influência do modelo médico-hegemônico, pressionam e buscam serviços e procedimentos especializados.

Desde a década de 1920, distintos países vêm estruturando sistemas nacionais de saúde orientados pelas premissas apresentadas no relatório Dawson, entre as quais se destaca a organização dos serviços em níveis de assistência - primário, secundário e terciário -, com complexidade crescente (NOVAES; MIR, 1990). No processo de implantação do SUS, foi introduzida nova terminologia para esses níveis de atenção, assumida, efetivamente, a partir da edição da NOAS SUS 01/2002. Partindo da mesma concepção hierárquica de sistemas de saúde, essa norma estabelece a regionalização como estratégia de hierarquização dos serviços de saúde, considerando para tal três níveis de atenção: atenção básica $(\mathrm{AB})$, média complexidade (MC) e alta complexidade (AC). Nesse contexto, o Ministério da Saúde conceituou média complexidade como o conjunto de "açôes e serviços que visam atender aos principais problemas e agravos de saúde da população, cuja prática clínica demande a disponibilidade de profissionais especializados e o uso de recursos tecnológicos, para o apoio diagnóstico e terapêutico" (BRASIL/MS, 2004).

Em decorrência da imprecisão conceitual, frequentemente as ações e serviços são classificados como de MC por exclusão, ou seja, tudo aquilo que "não cabe" 
como $\mathrm{AB}$ e que também não está na tabela da $\mathrm{AC}$. Destaque-se, ainda, que os conceitos dos níveis de complexidade denotam uma visão fragmentária de sistema e, ainda, centrada na produção de procedimentos (BRASIL/CONASS, 2007; GOTTEMS et al., 2008).

A maioria dos procedimentos classificados pelo Ministério da Saúde na MC subsidia o esclarecimento do diagnóstico das doenças, o que justifica seu caráter estratégico tanto para aumentar a resolutividade da $A B$, quanto para viabilizar a universalidade e integralidade do SUS. A MC se constitui em "verdadeiro anteparopara o bom desempenho do sistema de saúde. Nesse sentido, tanto pode avançar na qualidade da atenção, como pode constituir-se em nó crítico dos mais complexos" (GOTTEMS et al., 2008, p. 28-29). Dessa forma, o acesso aos serviços da MC se apresenta com um desafio para todos os gestores do SUS que, no entanto, assume diferentes dimensões, na dependência das características de cada estado, região, ou município.

O presente artigo teve como objetivo avaliar mecanismos utilizados pela gestão do SUS, no município de São Paulo, para garantir acesso à assistência de média complexidade e promover a integralidade da atenção.

\section{Métodos}

Para a realização desta pesquisa, optou-se pela estratégia do estudo de caso, que pode ser caracterizada como uma investigação empírica sobre um fenômeno contemporâneo complexo, em seu contexto, especialmente quando os limites entre o fenômeno e o contexto não estão claramente definidos (YIN, 2005).

Considerando os objetivos do estudo, delimitou-se o campo a uma instância administrativa da Secretaria Municipal de Saúde de São Paulo (SMS-SP). Essa corresponde a uma Supervisão Técnica de Saúde (STS) que abrange uma Subprefeitura, com uma população residente estimada em cerca de 430 mil habitantes. Os critérios para seleção da STS foram: existência de um número significativo de serviços públicos de saúde dos distintos níveis de complexidade e manutenção da unidade político-administrativa do território, desde a retomada do SUS no município. Essa escolha foi posteriormente negociada com assessoria do Gabinete da SMS-SP.

O estudo abrangeu a gestão municipal da cidade de São Paulo do período 2005 a 2008, tendo sido utilizadas as seguintes fontes de evidência: entrevistas com informantes-chave, grupo focal com usuários de serviço de saúde e observação direta. 
As entrevistas foram do tipo não-estruturadas, apoiadas em um roteiro básico contendo os pontos considerados centrais, em torno dos quais os autores exploraram questóes mais relevantes, o que permitiu detalhar temas de interesse. Essas foram conduzidas pelos pesquisadores, gravadas e em seguida transcritas por um assistente de pesquisa. Entrevistaram-se sete gestores da SMS-SP, tanto do nível locorregional quanto assessores do Gabinete, e um gestor da Secretaria de Estado da Saúde de São Paulo (SES-SP), assessor técnico do Gabinete.

O grupo focal foi realizado com o objetivo de complementar as informações obtidas por meio de outras fontes e explorou os conhecimentos de um grupo particular de usuários (MINAYO, 1994; CARLINI-COTRIM, 1996). Este foi composto por usuários de uma das Unidades Básicas de Saúde (UBS) da região estudada, portadores de hipertensão arterial sistêmica, doença crônica de alta prevalência, que, por suas características e critérios estabelecidos em programas institucionais, exige para seu acompanhamento exames e consultas especializadas. A partir da análise dos prontuários, foram selecionados e convidados 15 usuários; destes, sete participaram do grupo. $\mathrm{O}$ tema explorado no grupo foi centrado nas facilidades e dificuldades enfrentadas pelos participantes para utilizar serviços de especialidade na área de cardiologia.

A observação direta foi desenvolvida na UBS durante o processo de seleção e organização do grupo focal, em visitas a outros serviços de saúde, e em conversas com gestores e trabalhadores da região estudada.

A partir do trabalho de campo, realizou-se a classificação e agregação dos dados, tendo como referência a técnica da análise temática (BARDIN, 2004). A categoria analítica utilizada foi a integralidade da atenção. Considerando a polissemia desse termo, assumimos utilizá-lo em apenas um de seus múltiplos sentidos, qual seja, o modo de organizar os serviços e as práticas de saúde (MATTOS, 2001). De acordo com Giovanella e col. (2002), o conceito de integralidade contempla quatro dimensões, sendo uma delas a garantia de atenção nos três niveis de complexidade da assistência médica. Para esses autores, essa dimensão está relacionada diretamente à organização do sistema de saúde.

O projeto de pesquisa, que gerou os dados utilizados neste artigo, foi aprovado pelos Comitês de Ética em Pesquisa da Faculdade de Saúde Pública da USP e da Secretaria Municipal de Saúde de São Paulo, com base na Resolução no 196/96 do Conselho Nacional de Saúde. 


\section{O "gargalo" do SUS no município: a média complexidade}

Pode-se constatar um consenso entre os distintos relatos dos entrevistados quanto à necessidade de superar os obstáculos no acesso à média complexidade para se avançar na integralidade do sistema.

Apesar de a cidade São Paulo se constituir na maior e principal metrópole brasileira e concentrar importantes serviços de assistência médico-hospitalar do país, a média complexidade foi avaliada, pelos gestores municipais, como sendo o "gargalo", o "buraco" ou, ainda, o grande "obstáculo" do SUS no município.

No que se refere às consultas de urgência e emergência a impressão que a gente tem é que nós ofertamos mais do que o preconizado por qualquer parâmetro do Ministério. [...] No que se refere às consultas de complexidade primária, não é o suficiente pelo parâmetro do Ministério, mas também não é muito distante. No que se refere às consultas de média complexidade, aí tem um buraco, ai tem um déficit grande das consultas de média pra gente poder resolver. [...] O call center [...] distribui 100 mil consultas. [...] Mas o município precisa 300 mil. (assistente técnico da SES-SP).

O gargalo é o nível secundário, o acesso de especialidades e exames pra diagnóstico. [...] Um gargalo que vira até obstáculo, é mais do que um desafio. Porque, uma coisa é um desafio que te motiva e você vai e tenta superar. Outra coisa é um obstáculo paredão que 'puxa daqui eu não consigo nem passar. O que eu entendo como gargalo obstáculo é a parte da secundária (coordenador da atenção básica).

Os próprios gestores assinalaram alguns fatores que poderiam explicar, em parte, esse "buraco" na média complexidade. Chama a atenção o fato do acesso a procedimentos de alta complexidade ser, em muitas situações, relativamente mais fácil do que o acesso à média complexidade.

Até a alta complexidade você tem na cidade. Você consegue uma ressonância, você consegue até fazer um transplante hepático. Mas não consegue operar varizes! [...] Você pode dizer que é a vocação da cidade, a alta complexidade. Mas nós temos que ter alguma coisa também na média complexidade (coordenador regional).

A Tabela SUS foi lembrada, por um dos gestores, como um dos fatores que estariam associados a essa situação. Os valores pagos para procedimentos de alta complexidade são mais atrativos, o que induziria os prestadores privados a privilegiar a realização desses em detrimento daqueles da média complexidade.

Um dos principais problemas da rede, em termos de acesso, nem é o da tomografia. É ultrassonografia. São os exames de média complexidade. [...] Normalmente [são feitos] nos hospitais, nos serviços contratados. [...] A tabela também não paga bem 
[exames de média complexidade]. Então não é interessante pros conveniados contra-

tados, sabe? (assistente técnico do gabinete SMS-SP).

A baixa resolutividade dos serviços foi destacada por vários gestores entrevistados. Por um lado, apontou-se a necessidade de qualificar os encaminhamentos da atenção básica por meio de capacitação dos profissionais, médicos em particular, e da elaboração e utilização de protocolos. No entanto, de acordo com os próprios entrevistados, não houve nenhum avanço nessa direção.

A gente tem que ter um pouquinho mais de protocolo. [...] Nós temos poucos, alguns protocolos, todos na gaveta. Operando na prática, muito pouco [...]. Não conheço protocolos formais (coordenador regional).

Por outro lado, foi destacada, também, a baixa resolutividade dos ambulatórios de especialidades. Esta foi associada tanto à má qualidade do atendimento, quanto à dificuldade em realizar os exames necessários para o esclarecimento do diagnóstico e/ou definição da terapêutica.

Uma coisa que emperra é nossa capacidade de diagnóstico na especialidade. [...] Por exemplo, cardio. A quantidade de eco[cardiogramas] disponíveis, de eletro disponível é muito pequena. Então, o indivíduo fica tendo consulta no ambulatório de especialidade. Porque o tempo que ele leva pra conseguir consulta com cardio e firmar o diagnóstico e a conduta pra poder encaminhar também é grande. Porque nós temos um estreitamento da hora de conseguir os exames de especialidades (coordenador da atenção básica).

Essa questão repercute no acesso de novos pacientes aos ambulatórios de especialidade, na medida em que aumenta o número de retornos até a resolução do caso. E, para agravar ainda mais essa situação, muitas vezes, por interesse do serviço, do médico ou até do próprio paciente, esse "congela no ambulatório" e não volta para a UBS. Sendo assim,

apesar do ambulatório de especialidades ter fechado vagas pras unidades [...] não quer dizer que eu passei na unidade eu vou conseguir agendar em tempo hábil e que o ambulatório está devolvendo rapidamente. Não está! (coordenador da atenção básica).

De acordo com o assistente técnico da SES-SP, das 100 mil consultas de especialidade oferecidas mensalmente no call center apenas 20 mil são novas.

Vários gestores deram ênfase à condição particular das especialidades cirúrgicas, tais como ortopedia, urologia e cirurgia vascular, que apresentavam importante demanda reprimida. De acordo com seus relatos, a resolutividade dessas especialidades em ambulatórios isolados, sem retaguarda hospitalar é muito limitada. 
Passa no cirurgião vascular, ele fala: 'realmente, tem varizes, tem que operar. Volta pra unidade básica, [...] pra eles encaminharem pra um serviço que faz cirurgia vascular (coordenador regulação CRS).

O paciente é encaminhado ao ambulatório [X]. [...] Tem um fila de espera. Hoje, ortopedia tem aí 45 a 60 dias na fila esperando a consulta. Quando ele finalmente chega no dia abençoado da consulta, ao ser avaliado, o ortopedista [...] avalia aquele caso, e aquele caso é cirúrgico. Faz um novo encaminhamento e a pessoa novamente entra na regulação como se fosse um caso novo [...] para ser encaminhada para um ambulatório que tenha cirurgia (supervisor técnico).

Nesse sentido, dois gestores sugeriram que essas especialidades não deveriam ser mantidas em serviços ambulatoriais isolados, desvinculados de hospitais. $\mathrm{O}$ coordenador da regulação da SMS-SP questionou, inclusive, a ausência de um projeto político para enfrentar essa situação.

Tem que ter uma política institucional pra que as coisas realmente aconteçam. [...] Você identifica esses vários problemas, organiza uma área e não adianta mesmo você ter o cirurgião naquele ambulatório, sem que ele possa operar! [...] A gente nunca pode perder de vista essa linha de atenção, que é desde a porta de entrada até a resolução. Senão, a gente fica brincando o tempo todo, e o problema existe mesmo (coordenadora regulação SMS-SP).

Alguns entrevistados deram destaque ao fato de que a SMS-SP não havia assumido, ainda, a gestão de todos os serviços públicos localizados no município. Essa conjuntura representava mais um importante entrave à organização do sistema de saúde, como pode ser evidenciado no trecho abaixo.

[...] Essa diversidade de atores, que é um estado [SES] ainda muito forte na média complexidade, na alta complexidade. Então, você fica na dependência da política, dos humores da política. Onde pode, onde não pode. [...] Nós melhoramos muito, melhoramos muito na integração com o estado. Mas será sempre um grande desafio, visto que apesar da gestão plena a gente não tem a gestão de fato do serviço (coordenador regional).

\section{Os caminhos para acessar a média complexidade: o relato dos gestores}

Pode-se constatar, neste estudo, que o acesso aos serviços da média complexidade, no município de São Paulo, estava condicionado ao encaminhamento dos usuários por uma UBS. Inclusive os serviços de pronto-atendimento eram obrigados a encaminhar os pacientes que necessitavam de consulta ou exame especializado para uma UBS, pois somente esse serviço tinha acesso ao sistema informatizado 
de agendamento. Dessa forma, a SMS-SP transformou burocraticamente a UBS na porta de entrada do SUS no município.

Essa medida tinha, pelo menos, duas repercussões importantes. A primeira, dificultar o acesso de pacientes que, de fato, necessitavam de serviços especializados. E a segunda, de disputar e ocupar as poucas vagas disponíveis para consultas médicas das UBSs, com procedimentos meramente burocráticos, de "trocas de guia" de encaminhamentos.

O sistema de regulação municipal era responsável por coordenar e organizar todo o fluxo de usuários do SUS municipal. Além da Coordenadoria de Integração e Regulação do Sistema, no nível central da SMS-SP, existiam equipes de regulação no âmbito das CRSs e das STSs. No entanto, evidenciou-se que a estrutura desse sistema era limitada. "Até agora, a gente não tem tido nem perna nem vontade política de fazer realmente isso funcionar. [...] Nós somos poucas pessoas, as pessoas não são treinadas, não sabiam o que é regulação" (coordenador da regulação SMS-SP).

Essa limitação também foi realçada pelo gestor regional, ao afirmar que "[a estrutura] é o grande gargalo. [...] Na coordenadoria é realmente uma coisa complicada. [...] Nós somos muito poucos" (coordenador regulação CRS).

Embora os gestores entrevistados tivessem clareza das múltiplas atribuiçōes do sistema de regulação, associavam o contingenciamento de sua atuação ao número reduzido de técnicos que atuavam na área. Nesse contexto, assumiam que a prioridade do sistema vinha sendo a marcação de consultas, "a gente fica muito tempo na coisa de agendamento, de não perder a consulta” (coordenador regulação CRS).

Além das limitaçôes estruturais da própria SMS-SP, identificou-se outro entrave para a organização da regulação no município relacionado à coexistência de dois sistemas, independentes, para marcação de consultas e exames de especialidades. Um, sob a gestão da SMS-SP, que incluía os ambulatórios de especialidades vinculados ao município, alguns serviços privados sob seu comando, constituindo a denominada "agenda regulada". E o call center, sob a gestão da SES-SP, que incorporava os ambulatórios e hospitais de especialidades vinculados à SES-SP, além de alguns serviços universitários e privados, contratados pelo estado.

O call center foi organizado pela SES-SP "como uma encomenda que os ambulatórios precisaram para resolver seu problema regional. Só que ele virou uma solução para o município de São Paulo" (assistente técnico da SES-SP). Ainda, segundo esse entrevistado: 
o ideal no futuro é o call center ser municipalizado, aí a prefeitura tem tudo isso na mão. [...] $\mathrm{O}$ que ocorre é que a prefeitura ainda não conseguiu assumir pra si essa função do call center, como assumiu a regulação da urgência e emergência.

Os gestores municipais entrevistados relataram inúmeras dificuldades enfrentadas para realizar os agendamentos por meio do call center. A coordenação da regulação da SMS-SP reconhecia a importância de integrar os sistemas, mas ponderava que

o acesso é bom [com a SES-SP], a gente conversa, tem resposta, mas não vingou ainda. Assim, 'ah, agora nós vamos ter uma central única', por exemplo, imaginando que isso possa acontecer um dia. Mas aí, precisa realmente ter uma determinação de secretário pra secretário, pra fazer e aí institucionalizar. Isso ainda não aconteceu (coordenador regulação SMS-SP).

A informatização dos serviços de saúde foi a principal estratégia assumida pela gestão municipal para organizar o fluxo do acesso para a média complexidade no município. A incorporação dessa tecnologia tornaria possível o agendamento de consultas e exames on line, a partir das UBSs. Até então, esse agendamento era realizado pela STS, sem a participação da UBS e na ausência do usuário, o que acarretava dificuldades tanto para os usuários, quanto para o próprio sistema de saúde.

Outro aspecto importante a ser destacado refere-se à lógica de distribuição das vagas. Anteriormente à informatização, as vagas eram distribuídas por meio de cotas para as UBSs, a partir de um “estoque” disponível para cada CRS e seguindo critérios de regionalização. No início do processo de informatização, por decisão da SMS-SP, esse mecanismo foi alterado: "A secretária da saúde disse que o desperdício era muito grande, que ela ia acabar com a cota e com a regionalização" (coordenador da regulação da CRS).

A partir dessa medida, as UBSs passaram a ter acesso à agenda de todos os serviços vinculados ao SUS no município, independentemente de sua localização geográfica. Com isso, em muitas situações o usuário da zona sul da cidade poderia ser encaminhado para atendimento na zona leste, mesmo havendo a disponibilidade do serviço próximo ao seu local de moradia, o que manteve o “desperdício".

Eles têm agendado muito. Só que o índice de faltas [...] tem sido muito grande. [...] O que a gente está vendo é que, de repente, vai se auto-regular. [...] A unidade vai dizer assim: 'eu agendei o paciente lá pra [...], e o paciente não vai. Não adianta eu marcar mais lá (coordenador da regulação da CRS). 
O relato do coordenador da regulação do nível central também evidenciou que, na prática, a informatização não estava conseguindo organizar o fluxo de pacientes no sistema municipal de saúde, conforme esperado.

Eu ouvi dizer que às vezes o sistema é tão lento que não dá para você marcar na hora como foi proposto. [...] Eu ouvi dizer [...] que tem unidade que não consegue acessar muito bem o sistema, que ele é muito devagar e acaba ainda agendando no papel e depois coloca no sistema e depois vai avisar o paciente. Quer dizer, funcionou na mesma! (coordenador da regulação de SMS-SP).

\section{O caminho real: a vivência dos usuários}

A lógica de funcionamento da regulação, vigente até então, desconsiderava completamente o usuário. $\mathrm{O}$ agendamento era realizado burocraticamente para dia, hora e local disponibilizados pelo sistema, sem qualquer diálogo com as necessidades e possibilidades dos principais interessados. Essa situação contribuía para aumentar ainda mais o número de usuários faltosos e, por consequência, a ociosidade relativa dos serviços especializados. Segundo o assistente técnico da SES-SP, o índice de faltas nos serviços cujas vagas estavam disponibilizadas no call center era de 40 a $60 \%$, para as primeiras consultas.

Há um desperdício de um número grande de consultas. [...] Como o call center não dá a resposta imediata. O usuário é orientado a ir pra casa e voltar depois de um tempo pra saber quando foi agendada a consulta dele. Se ele não volta, essa consulta é reagendada e perdida. Muitas vezes, procura-se levar até a casa dele. Não consegue também. Outras vezes, é marcada a consulta, mas é distante de tempo e esquece. É impossível. [...] Ele mora na periferia da zona norte, se tiver que chegar às sete da manhã, num ambulatório da zona sul, não tem como chegar, impossível. Ele não sabe o caminho, vai ter que sair da casa dele três horas da manhã, pra poder chegar às sete no ambulatório (assistente técnico da SES-SP).

O grupo focal de usuários, que foi realizado no mesmo período em que a informatização dos serviços estava em curso, evidenciou que esses problemas ainda não haviam sido superados. É importante registrar que a discussão ficou centrada nos problemas enfrentados pelos participantes para lograrem acesso aos serviços especializados. Esses foram tão significativos que se sobressaíram, ocultando potenciais aspectos positivos.

Embora o tema apresentado se referisse ao atendimento na área de cardiologia, no desenvolvimento do grupo focal, foram agregadas informações sobre outras especialidades, o que possibilitou, em certa medida, uma visão mais abrangente 
sobre o acesso a serviços de média complexidade. Os temas que mais se destacaram foram agregados em três categorias: as regras estabelecidas pelos serviços; a distância dos serviços especializados; a demora para conseguir atendimento.

Logo após a apresentação do tema aos participantes, a primeira manifestação foi de crítica às regras de funcionamento e fluxo dos pacientes que eram estabelecidas unilateralmente pelos serviços e impostas aos usuários. Além de não serem previamente informados, em geral, os usuários se sentiam prejudicados, pois as mesmas vinham dificultando o acesso aos serviços.

A demora para conseguir o atendimento pretendido, seja realização de um exame ou consulta médica, foi o tema que assumiu maior relevância na discussão. Todos os participantes esperaram, ou ainda estavam esperando muito tempo para conseguir concretizar seu encaminhamento, sem qualquer informação sobre o tempo provável de espera ou o local do atendimento. Um deles dizia estar há cerca de um ano esperando uma consulta com cardiologista para poder realizar a cirurgia de catarata, que já estava agendada. Como não conseguiu, foi necessário reagendar a cirurgia.

Essa situação não se restringia à área de cardiologia. Foi lembrada também a demora para conseguir atendimento em outras áreas, em particular, na ortopedia: "Eu tô aqui também com um papel do ortopedista, que eu tô com um problema no joelho. [...] E já vai pra seis meses e não me chama. Não sei o que está acontecendo".

O longo tempo de espera não se limitava ao primeiro atendimento nas especialidades, estendendo-se ainda para a realização de exames complementares, necessários para elucidação do diagnóstico, bem como para as consultas de retorno.

[O pedido de exame] foi em novembro. Depois, fui chamado dia 14 de março [do ano seguinte]. Vai fazer dois meses já. [...] Eu nem sabia que eles ia me ligar, eles me ligaram pra eu fazer o exame e eu fui. Só, como fiz a 'esteira' lá, aí não tem vaga [para retorno]. Eu tô na lista de espera. [...] Tá tudo envelopado. Eu tenho que volta lá, [...] porque só ele [o cardiologista] tem que abrir o envelope.

E para piorar a situação, frequentemente, alguns exames solicitados pelos especialistas não eram disponibilizados no ambulatório de especialidades. Dessa forma, o usuário necessitava retornar à UBS de origem e, na dependência da dinâmica da unidade, entrar em nova fila para fazer o exame, aguardar o retorno do resultado, para só então levá-lo ao especialista. 
Demorou quase uns seis meses pra essa vaga sair. [...] Ele pediu o exame de sangue:

'A senhora faz em qualquer posto. No retorno, a senhora me entrega aqui'. Eu vim aqui, conversei com a enfermeira; ela autorizou, ela fez, depois eu vim pegar. [...] Eles marcaram a consulta lá, o retorno para dia 13 de agosto [daqui a três meses]. [...] E se eu tivesse alguma coisa?

A insatisfação do usuário com o atendimento recebido, decorrente tanto de sua baixa qualidade, quanto do tempo de espera, induzia o mesmo a buscar caminhos alternativos para resolver seus problemas, chegando inclusive a pagar por serviços privados.

Eu fui lá [no cardiologista], aí eu nem gostei da médica de lá. Ela me atendeu, ela nem mediu minha pressão. Aí ela pediu aquele exame lá de 'esteira'. [...] Aí, marcou logo pra mim fazer o exame, né? Mas, pra mim ter retorno com ela de novo, só agora dia 20 de junho [...]. Se não me encaminhar, então, eu vou pagar um cardiologista pra mim mostrar o exame.

Os usuários não tinham possibilidade de escolha, de decidir quando e para onde gostariam de ser atendidos. Frequentemente, aceitavam passivamente essa situação. Quando solicitavam que fossem encaminhados para serviços mais próximos ou de fácil acesso, ouviam dos responsáveis pela regulação da UBS que lá "não tem vaga" e que seriam encaminhados "para onde tem vaga".

Ficou evidenciado que parcela dos participantes do grupo focal utilizava um ambulatório de especialidades, localizado na mesma região geográfica a que pertencia a UBS e de fácil acesso. Contudo, em decorrência de uma alegada falta de vagas e/ou especialistas, esses usuários estavam sendo encaminhados de volta para a UBS de origem, para serem encaminhados a outros serviços. O ambulatório para o qual a UBS passou a encaminhar seus usuários era localizado em outra região da cidade. A distância geográfica foi identificada, por esse grupo, como importante obstáculo ao atendimento: "Agora eles manda lá pra esse fim de mundo, que eu nem sei [chegar]! [...] Pra esses quinto dos inferno. Longe!"

Apesar de termos realizado um único grupo focal, é importante ressaltar que todos os usuários presentes, sempre que puderam exercitar sua autonomia, utilizavam preferencialmente e por distintos motivos, serviços de saúde localizados na região da mesma Subprefeitura em que moravam. Vale lembrar que, nesse território, além da UBS de origem desses usuários, existiam três grandes ambulatórios de especialidades e dois hospitais especializados, todos públicos e estatais. 


\section{Discussão}

Este estudo evidenciou que, apesar da existência de um grande número de serviços de saúde especializados no município de São Paulo, os gestores do SUS e seus usuários continuam enfrentando importantes obstáculos para acessá-los, particularmente aqueles relacionados como de média complexidade. Em tese, um município com tantos serviços de saúde instalados em seu território não deveria enfrentar dificuldades semelhantes às apresentadas por municípios de pequeno porte, conforme já relatado em outras pesquisas (CECÍLIO et al., 2007; GOTTEMS et al., 2008).

A disponibilidade desses recursos é uma das condições necessárias para a garantia do acesso dos cidadãos aos serviços de saúde. Contudo, deve-se considerar que essa disponibilidade é apenas um dos fatores intervenientes nesse acesso. E, ainda, é importante destacar que acesso é um conceito complexo, apresentando múltiplas determinaçôes e variando de acordo com o contexto (FRENK, 1985; TRAVASSOS; MARTINS, 2004).

No caso estudado, pode-se constatar que o poder de utilização dos usuários do SUS não tem sido suficiente para ultrapassar a "resistência dos serviços", o que vem contribuindo para manter a condição de baixo acesso. E dada a dificuldade de se modificarem, em curto prazo, as características da população que interferem na utilização dos serviços de saúde, reforça-se a necessidade de se minimizarem os obstáculos dos serviços para melhorar o acesso dos cidadãos a todos os níveis de atenção à saúde, de forma a efetivar a integralidade da assistência à saúde.

É oportuno considerar, ainda, o papel que o modelo de atenção exerce na orientação da demanda aos serviços de saúde. Apesar dos avanços, o modelo que ainda prevalece hegemônico em nosso país é aquele centrado no médico, sob forte influência do complexo médico-industrial, que induz à demanda crescente e irracional de serviços com maior densidade tecnológica, tanto por parte dos profissionais de saúde, quanto pela própria população.

Nesta pesquisa, foi possível identificar algumas ações implementadas pela gestão municipal do SUS em São Paulo que, segundo o relato dos gestores, visavam a minimizar o "obstáculo paredão" e viabilizar o acesso à média complexidade, no sentido de garantir a continuidade do cuidado.

A informatização do sistema foi assumida, pela gestão municipal, como a principal estratégia para enfrentar o "gargalo" do SUS no município. Essa era 
vista como uma panacéia, capaz de solucionar todos os problemas relacionados

ao acesso de serviços especializados. Houve uma supervalorização do potencial dessa tecnologia para enfrentar problema tão complexo com várias determinações. Apesar da reconhecida importância da informatização para organização de serviços e fluxos, essa certamente não deveria ser adotada como medida isolada.

Nesse sentido, merece destaque o fato de que a informatização implementada não representou avanço no sentido de que o gestor municipal assumisse a gestão de todas as vagas disponibilizadas para o SUS. Ou seja, manteve-se um duplo sistema, agora informatizado, de agendamento e controle dos serviços de média complexidade, um sob gestão da SMS-SP e outro sob gestão da SES-SP.

Deve-se ressaltar que a regulação do SUS é uma ação complexa que não se limita à informatização e implantação de centrais de internação, consultas e exames, o que geralmente representa apenas uma adequação da demanda à oferta disponível. A regulação envolve distintos atores - gestores, prestadores e usuários -, com interesses muitas vezes conflitantes, implicando relações políticas, técnicas e de cuidado. Trata-se, assim, de um conjunto articulado de açôes que devem incorporar condução política, análise de situação e planejamento, com o objetivo de viabilizar o acesso do usuário aos serviços, visando à integralidade e resolutividade do sistema de saúde (BRASIL/MS, 2006; MENDONÇA et al., 2006).

Contudo, no município de São Paulo, evidenciou-se que a implementação de ações de regulação se restringiu à estruturação de um complexo regulador, com atuação centrada no controle de vagas para procedimentos especializados. A avaliação do coordenador da regulação explicitou a falta de prioridade política e técnica conferida pela SMS-SP a essa área: "até agora, a gente não tem tido perna nem vontade politica de fazer isso realmente funcionar".

Outro tema importante a ser incorporado nessa discussão refere-se à resolutividade da atenção básica. A relação entre a atenção básica e a média complexidade é um dos fatores condicionantes dessa resolutividade. Por um lado, a atenção básica depende do acesso a procedimentos disponíveis na média complexidade para aumentar sua resolutividade. Por outro, a baixa resolutividade da atenção básica aumenta a demanda para a média complexidade.

Aliamo-nos à posição, defendida por outros, de que o enfrentamento de problema dessa magnitude demanda mudanças organizacionais, combinando métodos de padronização, como protocolos, com transformações na prática 
da clínica (CAMPOS, 2006). A condução desse processo de mudança deveria contemplar a constituição de espaços democráticos de pactuação entre os distintos atores envolvidos. Contudo, não foram identificadas iniciativas, por parte da SMS-SP, no sentido de reorganizar os processos de trabalho, seja na atenção básica, seja nos ambulatórios de especialidades sob gestão municipal, apesar da concordância dos gestores quanto à baixa resolutividade desses serviços.

Neste estudo não foram identificados movimentos do gestor municipal no sentido de incorporar o cidadão-usuário como ator central do processo de construção do SUS em São Paulo. As longas filas de espera e a via crucis dos pacientes fazem parte do cotidiano da população usuária dos serviços públicos há muito tempo. A gestão municipal continua desenvolvendo suas ações centradas nos interesses dos serviços e/ou corporações, não considerando os interesses, desejos e necessidades dos cidadãos-usuários. Nesse sentido, constatou-se que algumas mudanças implementadas pela SMS-SP ocasionaram novos problemas para os usuários do SUS no município. Além da espera, eles passaram a enfrentar mais um obstáculo: a distância geográfica que teriam que percorrer para concretizar o atendimento. Essa situação foi agravada pela decisão da SMS-SP de "acabar com a regionalização", na medida em que, no caso estudado, a questão geográfica tinha influência no acesso aos serviços de saúde, como relatado em outras pesquisas (SILVA et al., 1995; OLIVEIRA et al., 2004).

\section{Considerações finais}

Pode-se constatar que a gestão do SUS no município de São Paulo pouco avançou no sentido de aliviar o "gargalo" da média complexidade e de incorporar a universalidade e a integralidade da atenção à saúde. Algumas açōes foram implementadas na última gestão da SMS-SP visando a superar esse obstáculo. Contudo, essas tinham caráter predominantemente racionalizador e tecnocrático, não dialogando com as demandas e necessidades de saúde dos cidadãos-usuários. $\mathrm{E}$, ao que parece, esse tema não foi assumido como prioridade da gestão municipal do período.

É oportuno lembrar que a informatização do sistema de saúde já havia sido iniciada na gestão anterior à estudada e não se restringia, em tese, à organização da referência e contrarreferência de usuários entre distintos serviços. Vale ressaltar, ainda, que a estruturação de sistemas regulatórios era condição, estabelecida pelo 
Ministério da Saúde, para que o município pudesse ser habilitado na condição de gestão plena do sistema e, por conseguinte, receber os repasses financeiros.

Independentemente dos distintos referenciais teórico-conceituais - "sistema local de saúde", "redes de atenção à saúde", "linhas do cuidado" (OPS, 1988; MENDES, 2001; FRANCO; MAGALHÁES JR, 2003) - e dos arranjos organizacionais propostos para a efetivação dos princípios do SUS, deve-se considerar que a média complexidade concentra parcela dos recursos necessários para garantir a integralidade da atenção à saúde. Nesse sentido, julgamos que o enfrentamento desse problema exige grande investimento por parte dos gestores do SUS. Para tanto, devem-se implementar ações articuladas, tanto no âmbito da macropolítica, quanto da micropolítica, orientadas pelas necessidades de saúde dos cidadãos-usuários.

\section{Referências}

BARDIN, L. Análise de Conteúdo. 3a ed. Lisboa: Edições 70, 2004.

BODSTEIN, R. Atenção Básica na agenda da saúde. Ciência e Saúde Coletiva, Rio de Janeiro, v. 7, n. 3, p. 401-412, 2002.

BRASIL. Ministério da Saúde. Secretaria de Atenção à Saúde. Departamento de Atenção à Saúde. Avaliação Normativa do Programa de Saúde da Família no Brasil: monitoramento da implantação e funcionamento das equipes de saúde da família: 2001-2002. Brasília: Ministério da Saúde, 2004. 140p.

BRASIL. Ministério da Saúde. SUS de A a Z. Brasília: Ministério da Saúde/Conasems, 2004. Disponível em: http://dtr2004.saude.gov.br/susdeaz/ Acesso em: 20 out. 2008.

BRASIL. Ministério da Saúde. Portaria n. 399, de 22 de fevereiro de 2006. Divulga o Pacto pela Saúde 2006 - Consolidação do SUS - e aprova as diretrizes operacionais do referido Pacto. Diário Oficial da União. Brasília, DF, 23 de fevereiro de 2006. Seção I, p.43.

BRASIL. Conselho Nacional de Secretários de Saúde. Assistência de Média e Alta Complexidade no SUS. Brasília: CONASS (Coleção Progestores, 9), 2007.

BRASIL. Ministério da Saúde. Secretaria de Atenção à Saúde. Departamento de Atenção à Saúde. Política Nacional de Atenção Básica. 4a. ed. Ministério da Saúde. Secretaria de Atenção à Saúde. Brasília: Ministério da Saúde, 2007.

CAMPOS, G.W.S. Clínica e saúde coletiva compartilhadas: teoria Paidéia e reformulação ampliada do trabalho em saúde. In: CAMPOS, G.W.S. et al. (Org.). Tratado de Saúde Coletiva. São Paulo: Hucitec; Rio de Janeiro: Fiocruz, 2006. p.53-92.

CECÍLIO, L.C.O. et al. O gestor municipal na atual etapa de implantação do SUS: característica e desafios. RECIIS - Revista Eletrônica de Comunicação Informação \& Inovação em 
Saúde, v.1, n.2, p.200-207, 2007. Disponível em: http://www.revista.cict.fiocruz.br/index. php/reciis/article/view/84/79. Acesso em: 15 nov. 2008.

CARLINI-COTRIM, B. Potencialidades da técnica qualitativa grupo focal em investigações sobre abuso de substâncias. Revista de Saúde Pública. São Paulo, v. 30, n. 3, p.285-293, 1996. ESCOREL, S. et al. O programa de Saúde da Família e a construção de um novo modelo para atenção básica no Brasil. Revista Panamericana de Salud Pública, v. 21, n. 2/3, p. 164-176, 2007.

FEUERWERKER, L. Modelos tecnoassistenciais, gestão e organização do trabalho em saúde: nada é indiferente no processo de luta para a consolidação do SUS. Interface - Comunicação, Saúde, Educação, Botucatu, v. 9, n. 18, p. 489-506, set./dez. 2005.

FRENK, J. El concepto y la medición de acessibilidade. Salud Publica de México, Ciudad de México, v. 27, n. 5, p.438-453, 1985.

FRANCO, T.B.; MAGALHÂES JR, H.M. Integralidade na assistência á saúde: a organização das linhas do cuidado. In: MERHY, E.E. et al. O Trabalho em Saúde: olhando e experienciando o SUS no cotidiano. São Paulo: Hucitec, 2003. p. 125-133.

GIOVANELLA, L. et al. Sistemas municipais de saúde e a diretriz da integralidade da atenção: critérios para avaliação. Saúde em Debate, Rio de Janeiro, v. 26, n. 60, p. 37-61, 2002. GOTTEMS, L.B.D et al. Análise da relação dos serviços de média complexidade com a rede básica do DF e entorno: buscando prioridades para ampliar acessos e resolubilidades (Relatório Final da Pesquisa). Universidade de Brasília, Universidade Católica de Brasília, Universidade Federal de Minas Gerais. Brasília, 2008.

HORTALE, V.A.; CONILL, E.M.; PEDROZA, M. Desafios na construção de um modelo para análise comparada de organização de serviços de saúde. Cadernos de Saúde Pública, Rio de Janeiro, v. 15, n. 1, p. 78-89, jan./mar., 1999.

MATTOS, R.A. Os sentidos da integralidade: algumas reflexôes acerca de valores que merecem ser defendidos. In: PINHEIRO, R.; MATTOS, R.A. (Org.). Os sentidos da integralidade na atenção e no cuidado à saúde. Rio de Janeiro: UERJ, IMS/Abrasco, 2001. p. 39-64.

MENDES, E.V. Os grandes dilemas do SUS. Salvador: Casa da Qualidade, 2001.Tomo II.

MENDES, E.V. O SUS que temos e o SUS que queremos. In: BRASIL. Conselho Nacional de Secretários de Saúde. Convergências e Divergências sobre a Gestão Regionalizada do SUS. Brasília: CONASS, 2004. p.28-61. Disponível em: http://www.conass.org.br/admin/ arquivos/documenta6.pdf. Acesso em: 10 set. 2008

MENDONÇA, C.S.; REIS, A.T.; MORAES, J.C. (Org.). A Política de Regulação no Brasil. Brasília: OPAS/MS (Série técnica desenvolvimento de sistemas e serviços de saúde; 12), 2006. MINAYO, M.C.S. Fase de trabalho de campo. In: $O$ desafio do conhecimento. Pesquisa qualitativa em saúde. 3a . ed. São Paulo: Hucitec, 1994. p. 105-196. 
NOVAES, H.M.; MIR, R.C. Sistemas locales de salud: um medio para la regionalización de los servícios de salud. In: PAGANINI, J.M.; MIR, R.C. (Ed.). Los Sistemas Locales de Salud: conceptos, métodos, experiencias. Washington, D.C.: Organización Panamericana de la Salud (Publicación Científica No. 519), 1990. p.147-158.

OLIVEIRA, E.X.G. et al. Acesso à internação hospitalar nos municípios brasileiros em 2000: territórios do Sistema Único de Saúde. Cadernos de Saúde Pública, Rio de Janeiro, v. 20, supl. 2, p. S298-309, 2004.

ORGANIZACIÓN PANAMERICANA DE LA SALUD. Desarrollo y fortalecimiento de los sistemas locales de salud en la transformación de los sistemas nacionales de salud (documento CD 33/14, resolución XV-XXXIII Del Comite Directivo, 30 sep. 1988). In: PAGANINI, J.M.; MIR, R.C. (Ed.). Los Sistemas Locales de Salud: conceptos, métodos, experiencias. Washington, D.C.: Organización Panamericana de la Salud (Publicación Científica No. 519), 1990. p. 5-20.

PIMENTA, A.L. Presidente do Cosems afirma que prefeituras investem mais que Estados e União no financiamento do SUS. Jornal do Cremesp. Edição 215, 7/2005. Disponível em: http://www.cremesp.com.br/?siteAcao=Jornal\&id=531. Acesso em: 25 set. 2008.

SANTOS, M.A.B.; GERSCHMAN, S. As segmentações da oferta de serviços de saúde no Brasil - arranjos institucionais, credores, pagadores e provedores. Ciência e Saúde Coletiva, Rio de Janeiro, v. 9, n. 3, p. 795-806, 2004.

SILVA, L.M.V. et al. O processo de distritalização e a utilização dos serviços de saúde: avaliação do caso de Pau da Lima, Salvador, Bahia, Brasil. Cadernos de Saúde Pública, Rio de Janeiro, v. 11, n. 4, p. 72-84, jan./mar. 1995.

TEIXEIRA, C.F. A mudança do modelo de atenção à saúde no SUS: desatando nós, criando laços. Saúde em Debate, Rio de Janeiro, v. 27, n. 65, p. 257-277, set./dez. 2003.

TEMPORÃO, J.G. (entrevista) Revista Conasems, ano II, n.23, p.5-12, mai./jun. 2007. Disponível em http://www.conasems.org.br/files/revista23.pdf. Acesso em: 25 set. 2008.

TRAVASSOS, C.; MARTINS, M. Uma revisão sobre os conceitos de acesso e utilização de serviços de saúde. Cadernos de Saúde Pública, Rio de Janeiro, v. 20, supl. 2, p. S190-S198, 2004.

YIN, R.K. Estudo de Caso: planejamento e métodos. $3^{\text {a }}$ ed. Porto Alegre: Bookman, 2005. 


\section{Abstract}

\section{The difficult access to secondary health care services: São Paulo city case study, Brazil} The population access to the secondary health care services is being pointed, by managers and researchers, as one of the challenges to the implementation of integrality in the Brazilian National Health System (SUS). This paper aims to evaluate the mechanisms used by SUS manager's, in the city of São Paulo, to guarantee medical assistance, from 2005 to 2008. The strategy of case study was chosen, using as data sources such as managers interviews, focus groups with SUS users, and participative observation. Thematic analysis was performed on health services organization, with theoretical references of the integrality concept. We tried to describe the path covered by the users to have access to the services, based on the view of users and managers. Secondary health care services were identified by managers as the "neck of a bottle" and one of the main obstacle to the SUS integrality. To overcome this situation, the municipal manager invested in the computerization of services, as an isolated step, and still, without considering user's needs. However, this technological incorporation had low impact on the improvement of the population access to the secondary health care services, which was confirmed by user's source. It is argued that to face such complex problem it will be necessary to articulate actions, not only in health politics but also in health services organization and also in the (re)organization of the working process in any other level of the health system.

> Key words: secondary health services; integrality; health management; Single Health System; health policy 